\title{
PEMBINAAN KEAGAMAAN MASYARAKAT DI KABUPATEN BONE MELALUI PROGRAM KKN MAHASISWI STIBA MAKASSAR
}

\section{COMMUNITY RELIGIOUS DEVELOPMENT IN BONE REGENCY THROUGH KKN STIBA MAKASSAR STUDENTS PROGRAM}

\author{
Hijrayanti Sari \\ Sekolah Tinggi Ilmu Islam dan Bahasa Arab (STIBA) Makassar \\ Email: hijrayantisari@stiba.ac.id \\ A. Hawariah \\ Sekolah Tinggi Ilmu Islam dan Bahasa Arab (STIBA) Makassar \\ Email: hawariah@stiba.ac.id
}

\begin{tabular}{|c|c|}
\hline Keywords : & ABSTRACT \\
\hline $\begin{array}{l}\text { Bone, Muslimah, KKN } \\
\text { STIBA Makassar, Dirosa }\end{array}$ & $\begin{array}{l}\text { The implementation of The Real Work Lecture (KKN) of students of } \\
\text { Sekolah Tinggi Ilmu Islam dan Bahasa Arab (STIBA) Makassar } \\
\text { aims to take a role in helping the Government of Bone Regency of } \\
\text { South Sulawesi Province in realizing the mission of mental and } \\
\text { spiritual development between religious people and carrying out tri } \\
\text { dharma higher education on the pillars of community service. The } \\
\text { method of implementing the KKN program begins by observing the } \\
\text { condition of the community using SOAR analysis. The work } \\
\text { program is carried out both online and offline. Online activities } \\
\text { include Taklim Fikih Wanita Pekanan and Kajian Muslimah with } \\
\text { the target of Muslim women with a younger age and have the } \\
\text { ability to access activities. While offline activities include } \\
\text { Bimbingan Islam Intensif and Dirosa with the target of mothers } \\
\text { who are unable to access activities through online. The enthusiasm } \\
\text { of the community from all activities that have been carried out is } \\
\text { quite large and becomes a recommendation so that there are still } \\
\text { continued activities for the establishment of built areas. }\end{array}$ \\
\hline \multirow{3}{*}{$\begin{array}{l}\text { Kata kunci : } \\
\text { Bone, Muslimah, KKN } \\
\text { STIBA Makassar, Dirosa }\end{array}$} & ABSTRAK \\
\hline & Pelaksanaan Kuliah Kerja Nyata (KKN) Mahasiswa Sekolah Tinggi \\
\hline & $\begin{array}{l}\text { Ilmu Islam dan Bahasa Arab (STIBA) Makassar ini bertujuan untuk } \\
\text { mengambil peran dalam membantu pemerintah Kabupaten Bone } \\
\text { Provinsi Sulawesi Selatan dalam mewujudkan misi pembinaan } \\
\text { mental dan spritual antar umat beragama serta melaksanakan Tri } \\
\text { Dharma Perguruan Tinggi pada pilar pengabdian masyarakat. } \\
\text { Metode pelaksanaan program KKN diawali dengan melakukan } \\
\text { pengamatan kondisi masyarakat dengan menggunakan analisis } \\
\text { SOAR. Program kerja dilaksanakan baik secara online maupun } \\
\text { offline. Kegiatan online meliputi Taklim Fikih Wanita Pekanan dan } \\
\text { Kajian Muslimah dengan target muslimah dengan usia lebih muda } \\
\text { dan mempunyai kemampuan untuk mengakses kegiatan. Sedangkan } \\
\text { kegiatan offline meliputi Bimbingan Islam Intensif dan Dirosa } \\
\text { dengan target ibu-ibu yang tidak mampu mengakses kegiatan } \\
\text { melalui daring. Antusiasme masyarakat dari semua kegiatan yang } \\
\text { telah dilaksanakan cukup besar dan menjadi rekomendasi agar tetap } \\
\text { ada kegiatan lanjutan untuk pembentukan daerah binaan. }\end{array}$ \\
\hline
\end{tabular}


Diterima: 16 Oktober 2021; Direvisi: 22 Desember 2021; Disetujui: 22 Desember 2021; Tersedia online: 31 Desember 2021

How to cite: Hijrayanti Sari, A. Hawariah. "Pembinaan Keagamaan Masyarakat di Kabupaten Bone Melalui Program KKN Mahasiswi STIBA Makassar", WAHATUL MUJTAMA': Jurnal Pengabdian Masyarakat Vol. 2, No. 2 (2021): 182-188. doi: 10.36701/wahatul.v2i2.438.

\section{PENDAHULUAN}

Kabupaten Bone merupakan salah satu kabupaten yang terletak di pesisir timur Provinsi Sulawesi Selatan dan berjarak sekitar 174 km dari Kota Makassar. Luas wilayahnya sekitar $4.559 \mathrm{~km}^{2}$ atau 9,78 persen dari luas Provinsi Sulawesi Selatan. Kabupaten Bone mempunyai garis pantai sepanjang $138 \mathrm{~km}$. Wilayah yang besar ini terbagi menjadi 27 kecamatan dan 372 desa/kelurahan. Ibukota Kabupaten Bone adalah Watampone.

Secara geografis, Kabupaten Bone berbatasan dengan beberapa wilayah, dari sebelah utara berbatasan dengan Kabupaten Wajo dan Soppeng, sebelah timur berbatasan dengan Teluk Bone, sebelah selatan berbatasan dengan Kabupaten sinjai dan Gowa, sebelah barat berbatasan dengan Kabupaten Maros, Pangkep, dan Barru.

Kabupaten Bone terletak pada posisi $4^{\circ} 13^{\prime}-5^{\circ} 6^{\prime}$ Lintang Selatan dan antara $119^{\circ} 42^{\prime}-120^{\circ} 30^{\prime}$ Bujur Timur. Letaknya yang dekat dengan garis khatulistiwa menjadikan Kabupaten Bone beriklim tropis. Sepanjang tahun 2014, kelembaban udara berkisar antara $77-86 \%$ dengan suhu udara $24,4^{\circ} \mathrm{C}-27,6{ }^{\circ} \mathrm{C}$. Letaknya yang dekat dengan garis katulistiwa menjadikan Kabupaten Bone beriklim tropis. Sepanjjang tahun 2014 kelembaban udara berkisar antara 77-86 persen dengan suhu udara $24,4^{\circ} \mathrm{C}-27,6^{\circ} \mathrm{c}$. Wilayah Kabupaten Bone terbagi menjadi dua tipe hujan, yaitu tipe hujan monsoon dan tipe hujan local.

Berdasarkan Survei Sosial Ekonomi Nasional Kor, Maret 2015, Angka Partisipasi Murni (APM) tertinggi berada pada jenjang SD/MI dengan APM mencapai 98,57 sedangkan Angka Partisipasi Kasar (APK) tertinggi berada pada jenjang SD/MI dengan APK 112,87. Menurut Dinas Pendidikan Nasional dan Kementriaan Agama Kabupaten Bone pada tahun 2015, terdapat 474 TK, 669 SD, 88 MI, 122 SMP, 87 MTS, 37 SMA, 24 SMK, dan 40 MA. Pada tahun 2019 terdapat 4 Rumah Sakit di Kabupaten Bone, 38 Puskesmas, 942 Posyandu, 13 Klinik, dan 156 Polindes yang tersebar di seluruh Kabupaten Bone.

Sarana peribadatan merupakan sarana mengisi kebutuhan rohani yang perlu disediakan, ${ }^{1}$ dimana mayoritas agama masyarakat Kabupaten Bone adalah Islam. Hal ini diiringi dengan bertambahnya jumlah tempat peribadatan agama Islam yang ada di Kabupaten Bone sebanyak 1.447 mesjid berdasarkan data tahun

${ }^{11}$ Putri, Sri Ujiana and Dewi Indriani, "Safari Dakwah Berbasis Islam Mahasiswi Kkn Stiba Makassar di Dusun Dasan Bagik, Lombok Timur", WAHATUL MUJTAMA': Jurnal Pengabdian Masyarakat 2.1 (2021): 11-20

Hijrayanti Sari, A. Hawariah. Pembinaan Keagamaan Masyarakat ... ... 
2019 dan 1.584 musalla yang tersebar di seluruh wilayah kecamatan dan desa di Kabupaten Bone.

Masyarakat Kabupaten Bone, sebagaimana masyarakat kabupaten lainnya di Provinsi Sulawesi Selatan pada umumnya, merupakan pemeluk agama Islam yang taat, kehidupan mereka selalu diwarnai oleh keadaan yang bersifat religius. Kondisi ini ditunjukkan dengan banyaknya tempat-tempat ibadah dan pendidikan agama Islam. Keadaan ini sangat potensial untuk diadakannya pembinaan keislaman secara lebih intensif untuk meningkatkan kualitas keislaman masyarakat Kabupaten Bone. Meskipun demikian, di kota Watampone juga ada Gereja dimana pemeluk agama lain cukup leluasa untuk menunaikan ibadahnya ${ }^{2}$

Melihat potensi di atas, ditetapkan tujuan pelaksanaan Kuliah Kerja Nyata (KKN) Mahasiswa Sekolah Tinggi Ilmu Islam dan Bahasa Arab (STIBA) Makassar, yaitu:

(1) untuk mengambil peran dalam membantu pemerintah Kabupaten Bone Provinsi Sulawesi Selatan dalam mewujudkan misi pembinaan mental dan spritual antar umat beragama;

(2) untuk meningkatkan kesadaran sosial dan dakwah mahasiswa STIBA Makassar dalam berkontribusi pada peningkatan Sumber Daya Manusia (SDM) masyarakat di Kabupaten Bone;

(3) melaksanakan Tri Dharma Perguruan Tinggi pada pilar pengabdian masyarakat.

Program KKN diawali dengan analisis kebutuhan program pemberdayaan masyarakat menggunakan analisis SOAR sebagai berikut:

(1) strength, dimana Kabupaten Bone berpenduduk mayoritas muslim. Selain itu, juga didukung dengan keberadaan mahasiswa KKN yang telah dibekali dengan pelatihan dakwah;

(2) oppurtunities, dimana pemerintah Kabupaten Bone mendukung peningkatan dan aktifitas keagamaan;

(3) aspiration, adanya semangat belajar muslimah di daerah Kabupaten Bone;

(4) result, peningkatan kualitas beragama muslimah Kabupaten Bone .

Sebelumnya, telah banyak program Pengabdian kepada Masyarakat (PkM) dengan model KKN, di antaranya adalah:

1. PkM yang dilaksanakan oleh Asnawati dan kawan-kawan di Gorontalo, telah melaksanakan program kerja tim KKN: Kajian Jumat, Tahfiz Qur'an Harian, Pendidikan Al-Qur'an Orang Dewasa (Dirosa), Menghafal Hadis Kitabul Jami', Pengajaran Bahasa Arab, TPA/TPQ, Tahsin (perbaikan bacaan). ${ }^{3}$

2. Pelaksanaan PkM di Bangka Belitung oleh Hijrayanti dan kawan-kawan, beberapa kegiatan virtual yang dilaksanakan bagi para Muslimah adalah: 1) Taklim pekanan virtual Muslimah; 2) Pembinaan DIROSA; 3) Tahsin dan

2 Admin, “Agama, Adat, Budaya, Pendidikan, Dan Kesehatan Di Kabupaten Bone,” 2019, https://bone.go.id/2019/12/25/agama-adat-budaya-pendidikan-dan-kesehatan-di-kabupaten-bone/.

3 Asnawati Patuti, Riska, and Eka Syahriani, "Program Belajar Islam Intensif Bagi Muslimah Di Desa Kenari, Kabupaten Pohuwato, Gorontalo” 2, no. 1 (2021): 70-82.

Hijrayanti Sari, A. Hawariah. Pembinaan Keagamaan Masyarakat ... ... 
Tahfiz Online; 4) Pengajaran Bahasa Arab Virtual; 5) Belajar Islam Intensif Online; dan 6) Webinar Pra Ramadhan. ${ }^{4}$

Beberapa kegiatan yang telah disebutkan di atas memberikan hasil yang baik dan dampak yang signifikan bagi masyarakat di Gorontalo dan Bangka Belitung. Hal ini kemudian mendorong para mahasiswi KKN untuk mengadakan beberapa program serupa di Kabupaten Bone.

\section{PEMBAHASAN}

\section{Belajar Islam Intensif}

Lawati dalam skripsinya berhasil menemukan bahwa banyak orang tua yang tidak memberikan contoh teladan yang baik seperti sholat wajib lima waktu. Kebanyakan anak di desa Tanah harapan ini mengaji di TPQ karena orang tua mereka banyak yang tidak paham tentang agama dan terlalu sibuk dengan aktifitasnya masing-masing. ${ }^{5}$ Dari hal inilah sehingga pelaksanaan PkM mengupayakan untuk mampu memberikan solusi. Maka dibuatlah program kerja belajar Islam intensif.

Belajar Islam intensif merupakan program kerja yang dirancang untuk mengajarkan agama Islam, hal-hal yang pokok dalam Islam dan wajib untuk diketahui oleh setiap muslim. Kegiatan dilaksanakan di rumah warga dan musala serta dilaksanakan setiap pekan. Kegiatan ini lebih banyak di isi dengan diskusi karena antusias peserta yang sering bertanya terkait persoalan kehidupan seharihari. Hasil dari program ini adalah ibu-ibu peserta berupaya menjalankan kehidupan sehari-harinya sesuai dengan ajaran Islam.

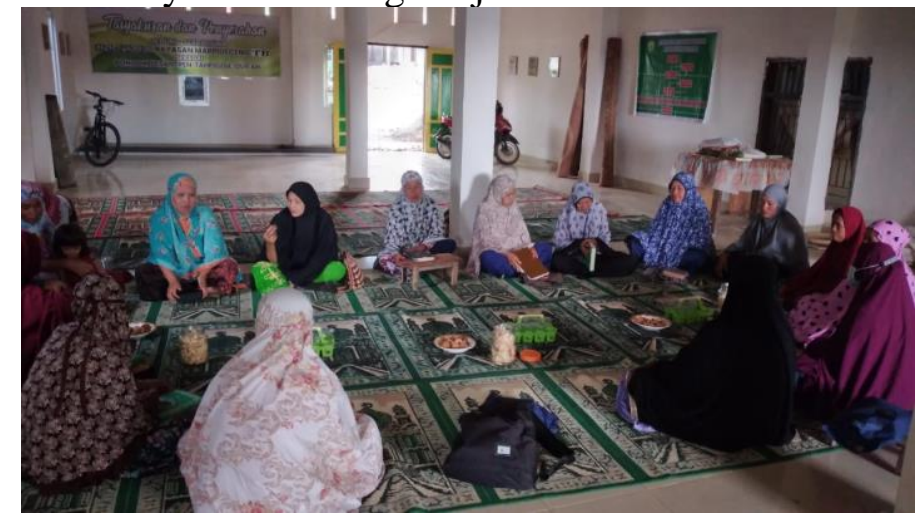

\section{Dirosa}

Gambar 1. Kegiatan Belajar Islam intensif

Dirosa adalah metode belajar Al-Qur'an untuk usia dewasa. Sistem yang digunakan adalah klasikal dengan target 20 pertemuan. Dalam pelaksanaan metode belajar ini menggunakan ritme tertentu yang memudahkan peserta usia lanjut mudah mengikuti pembelajaran Al Qur'an. Tujuan program pembinaan

4 Hijrayanti Sari et al., "Taklim Virtual Muslimah Pada Masa Pandemi Covid-19 Di Wilayah Provinsi Bangka Belitung” 2, no. 1 (2021): 102-15.

5 Siti Rohaenah Lawati, "Problematika Orang Tua Dalam Menanamkan Nilai-Nilai Keagamaan Pada Anak Di Desa Tanah Harapan Kec Mukomuko Kab Mukomuko" (Isntitut Agama Islam Negeri Bengkulu, 2018).

Hijrayanti Sari, A. Hawariah. Pembinaan Keagamaan Masyarakat ... ... 
Dirosa antara lain:(1) Untuk meningkatkan semangat seseorang dalam mempelajari dan mengajarkan Al-Qur'an; (2) Memberikan tambahan wawasan dasar-dasar keislaman kepada peserta Dirosa; dan (3) Untuk memberikan pembelajaran baca Al-Qur'an kepada remaja dan orang dewasa agar dapat membaca sesuai ilmu dan kaidah tajwid. ${ }^{6}$

Setelah mengikuti kegiatan terlihat perubahan yang baik dalam membaca Al-Qur'an. Mengajarkan Al Qur'an pada ibu-ibu usia lanjut cukup memberikan kesan kepada mahasiswa KKN karena adanya peserta yang tidak paham bahasa Indonesia sehingga mahasiswa menjelaskan dengan menggunakan bahasa daerah.

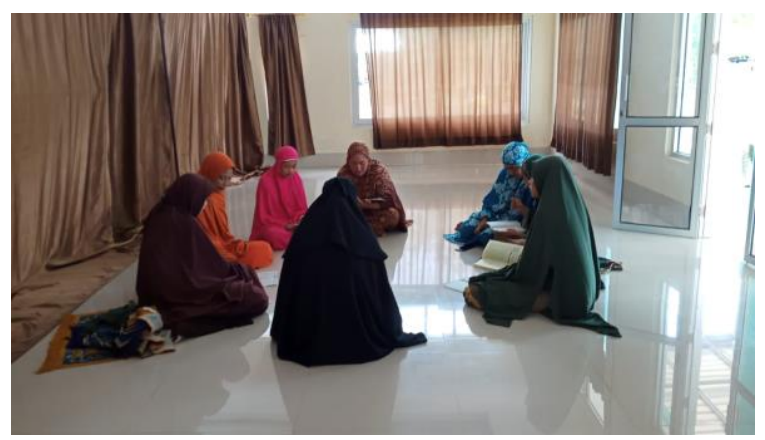

Gambar 2. Kegiatan Dirosah

\section{Taklim Fikih Wanita Pekanan}

Taklim Fikih Wanita Pekanan adalah salah satu kegiatan yang dilakukan setiap pekan dengan memberikan materi seputar fikih wanita kepada muslimah kabupaten Bone. Menurut Zulfiah kegiatan fikih wanita bertujuan untuk menambah wawasan keislaman serta meningkatkan iman dan takwa muslimah. ${ }^{7}$ Kegiatan dilaksanakan secara virtual dengan target peserta adalah muslimah remaja, mahasiswi atau seumurannya. Para peserta tampak antusias mengikuti kegiatan dengan banyaknya pertanyaan-pertanyaan yang diajukan kepada pemateri. Kegiatan ini memberikan hasil yang baik bagi muslimah peserta dimana pemahaman mereka akan hukum fikih yang berkaitan dengan wanita semakin baik dan diaplikasikan dalam kehidupan mereka.

\section{KAMUS (Kajian Muslimah)}

Kajian Muslimah adalah kegiatan yang dilaksanakan sebagai bekal muslimah Bone menyambut bulan suci Ramadan. Hal ini dilaksanakan agar muslimah Bone bisa mengambil banyak peluang pahala pada bulan Ramadhan. Peserta tampak semangat karena kegiatan dilaksanakan menjelang masuknya bulan Ramadhan dan dipaparkan dengan cukup ringan oleh mahasiswa KKN.

\footnotetext{
${ }^{6}$ Wijaya, Hendra, et al., "Pembelajaran Metode Dirosa di Desa Majannang Kabupaten Gowa", WAHATUL MUJTAMA': Jurnal Pengabdian Masyarakat 1.1 (2020): 67-74.

${ }^{7}$ Sam, Zulfiah, et al., "Pelaksanaan Kkn Kemanusiaan Mahasiswi Stiba Makassar Di Kelurahan Malunda, Kabupaten Majene”, WAHATUL MUJTAMA': Jurnal Pengabdian Masyarakat 2.1 (2021): 1-10
}

Hijrayanti Sari, A. Hawariah. Pembinaan Keagamaan Masyarakat ... ... 


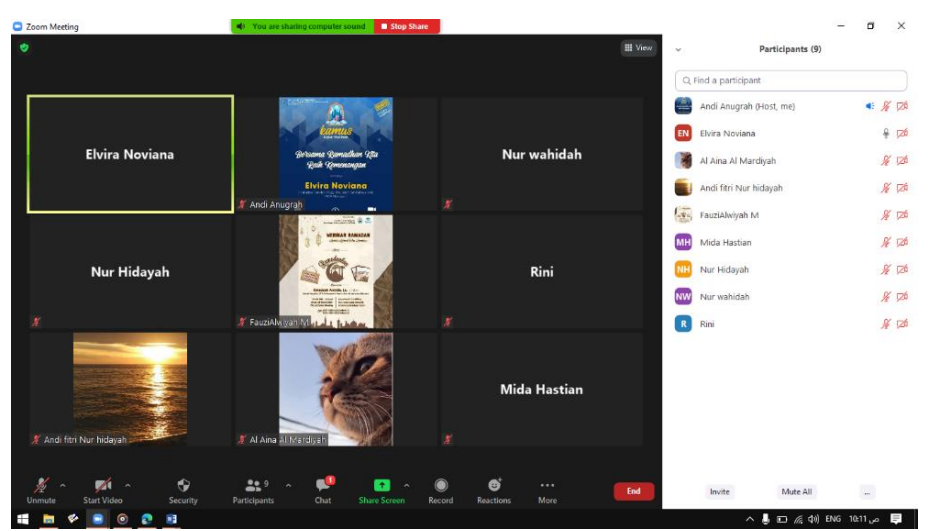

\section{KESIMPULAN}

Gambar 3. Kegiatan Dirosa

Berdasarkan uraian pelaksanaan program kerja KKN STIBA Makassar di Kabupaten Bone, dapat disimpulkan bahwa kegiatan atau program kerja yang telah dirancang dapat terlaksana dengan baik dan menunjukkan hasil yang baik dalam rangka meningkatkan kualitas keislaman masyarakat Bone baik dari segi membaca Al-Qur'an, pemahaman tentang fikih and lainnya. Hal tersebut tidak lepas dari dukungan dan antusias masyarakat dalam mendukung kegiatan KKN STIBA Makassar ini. Program kerja yang telah dilaksanakan selama masa KKN oleh KKN STIBA Makassar direkomendasikan untuk ditindaklanjuti oleh lembaga dakwah setempat.

\section{DAFTAR PUSTAKA}

Al-Jauziyyah, Ibnu al-Qayyim. Zādu al-Ma 'ād fì Hadyi Khairi al- 'Ibād. Jilid 5. Cet. XXVII. Beirut: Mu'assasah al-Risālah, 1994.

Admin. "Agama, Adat, Budaya, Pendidikan, Dan Kesehatan Di Kabupaten Bone," 2019. https://bone.go.id/2019/12/25/agama-adat-budaya-pendidikan-dankesehatan-di-kabupaten-bone/.

LAWATI, SITI ROHAENAH. "PROBLEMATIKA ORANG TUA DALAM MENANAMKAN NILAI-NILAI KEAGAMAAN PADA ANAK DI DESA TANAH HARAPAN KEC MUKOMUKO KAB MUKOMUKO.” Isntitut Agama Islam Negeri Bengkulu, 2018.

Patuti, Asnawati, Riska, and Eka Syahriani. "PROGRAM BELAJAR ISLAM INTENSIF BAGI MUSLIMAH DI DESA KENARI , KABUPATEN POHUWATO, GORONTALO" 2, no. 1 (2021): 70-82.

Putri, Sri Ujiana and Dewi Indriani, "Safari Dakwah Berbasis Islam Mahasiswi Kkn Stiba Makassar di Dusun Dasan Bagik, Lombok Timur", WAHATUL MUJTAMA': Jurnal Pengabdian Masyarakat 2.1 (2021): 11-20

Sam, Zulfiah, et al., "Pelaksanaan Kkn Kemanusiaan Mahasiswi Stiba Makassar

Hijrayanti Sari, A. Hawariah. Pembinaan Keagamaan Masyarakat ... ... 
- JURnal $\quad$ WAHATUL MUJTAMA': Jurnal Pengabdian Masyarakat

WAHATUL Vol. 2, No. 2 (2021): 182-188

MUJTAMA'

Di Kelurahan Malunda, Kabupaten Majene", WAHATUL MUJTAMA': Jurnal Pengabdian Masyarakat 2.1 (2021): 1-10

Sari, Hijrayanti, M Amirullah, Sekolah Tinggi, Ilmu Islam, and Arab Stiba. "TAKLIM VIRTUAL MUSLIMAH PADA MASA PANDEMI COVID-19 DI WILAYAH PROVINSI BANGKA BELITUNG" 2, no. 1 (2021): 10215.

Wijaya, Hendra, et al., "Pembelajaran Metode Dirosa di Desa Majannang Kabupaten Gowa", WAHATUL MUJTAMA': Jurnal Pengabdian Masyarakat 1.1 (2020): 67-74. 